\title{
Reduction in Opioid- and Cannabinoid-Induced Antinociception in Rhesus Monkeys after Bilateral Lesions of the Amygdaloid Complex
}

\author{
Barton H. Manning, ${ }^{1}$ Noah M. Merin, ${ }^{2}$ lan D. Meng, ${ }^{3}$ and David G. Amaral ${ }^{2}$ \\ ${ }^{1}$ Department of Neuroscience, Merck Research Laboratories, Merck \& Company, West Point, Pennsylvania 19486-0004, \\ 2Department of Psychiatry and Center for Neuroscience, University of California, Davis, Davis, California 95616, and \\ ${ }^{3}$ Department of Neurology, University of California, San Francisco, San Francisco, California 94143-0453
}

The amygdaloid complex is a prominent temporal lobe region that is associated with "emotional" information processing. Studies in the rodent have also recently implicated the amygdala in the processing and modulation of pain sensation, the experience of which involves a considerable emotional component in humans. In the present study, we sought to establish the relevance of the amygdala to pain modulation in humans by investigating the contribution of this region to antinociceptive processes in nonhuman primates. Using magnetic resonance imaging guidance, the amygdaloid complex was lesioned bilaterally in six rhesus monkeys (Macaca mulatta) through microinjection of the neurotoxin ibotenic acid. This procedure resulted in substantial neuronal cell loss in all nuclear subdivisions of this structure. In awake unoperated control monkeys, systemic administration of the prototypical opioid morphine or the cannabinoid receptor agonist WIN55,212-2 produced dose-dependent antinociception on a warm-water tail-withdrawal assay. The antinociceptive effects of each drug were reversible with an appropriate antagonist. In monkeys with bilateral amygdala lesions, however, the antinociceptive effects of each drug were significantly reduced. These results constitute the first causal data demonstrating the necessity of neurons in a specific brain region for the full expression of opioid- and cannabinoid-induced antinociception in the primate. Because our amygdala-lesioned monkeys exhibited both a reduction in antinociception and a reduction in behavioral indices of fear (Emery et al., 2001), the possibility should be considered that, in the primate, "antinociceptive circuitry" and "fear circuitry" overlap at the level of the amygdala.

Key words: pain; analgesia; antinociception; opiate; opioid; morphine; cannabinoid; WIN55,212-2; amygdala; amygdaloid complex; lesion; ibotenic acid; fear
The mammalian brain contains a pain-modulation system that controls the transmission of nociceptive signals through the dorsal horn of the spinal cord (Willis and Westlund, 1997; Fields and Basbaum, 1999). The most extensively studied components of this neural system are located in the brainstem and spinal cord and include circuits descending from the midbrain periaqueductal gray matter (PAG) to the rostral ventromedial medulla (RVM) and dorsolateral pontine tegmentum (DLPT). Axons from painmodulating neurons in the RVM and DLPT descend, in turn, to the spinal and trigeminal dorsal horns in which they exert bidirectional control over the transmission of nociceptive signals. This system provides a means by which psychological states can influence pain perception (Hirakawa et al., 2000). Moreover, it is clear that the antinociceptive effects of drugs such as opioids (e.g., morphine), cannabinoids, and nicotinic cholinergic agonists are attributable, in part, to their actions on this system (Bitner et al., 1998; Manning, 1998; Meng et al., 1998).

In recent years it has become clear that the brainstem and

Received Feb. 16, 2001; revised July 11, 2001; accepted July 11, 2001.

This work was supported by the Medical Research Council of Canada, National Institutes of Health (United States Public Health Service Grants MH 41479, MH 57502, RR 00169, and NS 10816), and the Life Sciences Research Foundation. Part of this work was performed at the California Regional Primate Research Center (Davis, CA). We thank John Ruys and Phil Allen for expert technical assistance. We also thank Dr. Nathan Emery for helpful discussions and Dr. Jeffrey A. Vivian for invaluable advice regarding tail-withdrawal testing in rhesus monkeys.

Correspondence should be addressed to Dr. Barton H. Manning, Department of Neuroscience, Merck Research Laboratories, 770 Sumneytown Pike, WP46-300, West Point, PA 19486-0004. E-mail: barton_manning@merck.com.

Copyright $(\odot 2001$ Society for Neuroscience $0270-6474 / 01 / 218238-09 \$ 15.00 / 0$ spinal cord comprise only part of the mammalian painmodulation system. Several forebrain regions are also capable of eliciting antinociception on direct application of opioids (Manning et al., 1994; Burkey et al., 1996), and neuronal activity in some of these regions is necessary for the full antinociceptive effect of systemically administered morphine. For example, morphine antinociception is strongly reduced by manipulations that disrupt neuronal activity in the posterior hypothalamic nucleus (Manning and Franklin, 1998) or rostral agranular insular cortex (Burkey et al., 1996). These effects occur despite the fact that the systemically circulating morphine remains capable of binding to opioid receptors in other pain-modulating regions such as the PAG or RVM.

The amygdaloid complex is another forebrain region that plays an important role in antinociception. Located in the anterior temporal lobe in humans and nonhuman primates, the amygdala has been implicated in emotional information processing. This includes the attribution of emotional significance to "primary" rewards and punishers (i.e., events that are intrinsically rewarding or punishing), the association of "neutral" sensory stimuli with events of emotional significance (Holland and Gallagher, 1999), and the coordination of emotional and social behavior (Aggleton, 1993; LeDoux, 1995; Davis, 1998; Emery and Amaral, 2000). The profile of neuroanatomical connections associated with the amygdala makes this region well positioned to receive highly processed multimodal sensory information, attribute emotional significance to this information, and coordinate appropriate behavioral, visceral, and autonomic reactions. 
It was in this context that we demonstrated that the analgesic effect of systemically administered morphine in rats is strongly reduced by inactivation of neurons originating from the central nucleus of the amygdala (Ce) (Manning and Mayer, 1995a,b; Manning, 1998). These findings are consistent with both the role of the amygdala in coordinating fear-induced antinociception (i.e., in the normal, un-drugged animal) (Helmstetter, 1992) and the fact that this brain region receives considerable nociceptive input from the spinal cord via relays in the brainstem (Bernard et al., 1992). The findings also are consistent with the general role of the amygdala in fear and defense reactions and the fact that the experience of pain in humans involves a significant emotional component (Rainville et al., 1997). This prompted us to propose that the amygdala be incorporated into current models of endogenous pain-modulatory circuitry (Manning, 1998).

Although it is clear that great strides have been made in understanding the neural circuitry underlying pain modulation, most studies relating to the neuroanatomy and neurochemistry of this system have been performed in rodents. Although the neuroanatomical structures involved in pain modulation have been phylogenetically conserved across all mammals, functional evidence for the contribution of these structures to pain modulation in humans and nonhuman primates is scant. There is evidence suggesting that electrical or pharmacological activation of PAG neurons can inhibit pain in humans (Hosobuchi et al., 1977; Richardson and Akil, 1977; Gybels and Kupers, 1990) and nonhuman primates (Pert and Yaksh, 1974; Gerhart et al., 1984; Lin et al., 1994), but definitive studies demonstrating which painmodulating circuits (as defined in the rodent) are critical for the action of "analgesic" drugs have not been performed in the primate.

In the present experiments, we assessed the contribution of the amygdaloid complex to antinociceptive processes in the rhesus monkey. Specifically, we were interested in determining whether the primate amygdala, like the rodent amygdala, is required for the full antinociceptive effect of systemically administered morphine. In addition, we were interested in assessing the contribution of the amygdala to the antinociceptive effects of the cannabinoid receptor agonist WIN55,212-2. Because we (Meng et al., 1998) and others (Martin et al., 1998) have shown that cannabinoids produce antinociception, in part, by interacting with similar pain-modulating circuits as those acted on by morphine, we felt it reasonable to hypothesize that the amygdala also contributes to cannabinoid-induced antinociception. Accordingly, we hypothesized that, as compared with control monkeys, both morphineinduced and cannabinoid-induced antinociception would be significantly reduced in monkeys with large bilateral lesions of the amygdaloid complex.

\section{MATERIALS AND METHODS}

\section{Subjects}

These experiments were performed at the California Regional Primate Research Center (CRPRC) in Davis, CA. All protocols that were used in these studies were evaluated by and approved by the Institutional Animal Care and Use Committee at the University of California, Davis. Twelve adult male, experimentally naive, rhesus monkeys (Macaca mulatta) were randomly assigned to receive either bilateral ibotenic acid lesions of the amygdala (A-IBO group; $n=6$; mean age, $6.79 \pm 0.42$ years; mean weight, $11.65 \pm 0.36 \mathrm{~kg}$ ) or to act as unoperated controls (control group; $n=6$; mean age $=6.58 \pm 0.3$ years; mean weight, $9.81 \pm 0.5 \mathrm{~kg}$ ). Each monkey was born and raised in one of 12 half-acre outdoor enclosures containing $\sim 70$ animals. After assignment to each experimental condition, the animals were relocated to individual housing in rooms with automatically regulated lighting ( $12 \mathrm{hr}$ light/dark cycle) and temperature.
The animals were fed on a diet of monkey chow (Ralston Purina, St. Louis, MO) supplemented with fruit and vegetables, and water was available ad libitum.

\section{Surgery}

Magnetic resonance imaging. Because of the substantial interanimal variability in the size and shape of the rhesus monkey brain, the location of the amygdala in each animal was determined using magnetic resonance imaging (MRI) (Saunders et al., 1990; Alvarez-Royo et al., 1991; Rebert et al., 1991). Preliminary to the MRI, small glass beads filled with copper sulfate (which are highly visible with T1-weighted imaging) were cemented to the skull at known stereotaxic coordinates to serve as fiducial marks. The monkey was tranquilized with ketamine hydrochloride ( 8 $\mathrm{mg} / \mathrm{kg}$ ), its head was shaved, a tracheal cannula was inserted, and then the monkey was placed into an MRI-compatible stereotaxic apparatus (Crist Instruments, Damascus, MD). The subject was mechanically respirated and brought to a surgical level of anesthesia using isoflurane $(1-2 \%)$. A midline incision of the scalp was made, and the muscles and fascia were reflected. Two copper sulfate ( $2 \%$ solution)-filled glass beads (diameter, $3 \mathrm{~mm}$ ) were attached to the skull using dental acrylic at predetermined positions (A24 and A18 from interaural 0).

Two weeks after the bead implant surgery, the subjects underwent MRI analysis. The subjects were anesthetized with Telazol $(10 \mathrm{mg} / \mathrm{kg})$ and placed in an MRI compatible stereotaxic apparatus. The brain was imaged using a Phillips $1.5 \mathrm{~T}$ Gyroscan magnet. Sections were taken using a T1 weighted Inversion Recovery pulse sequence $(\mathrm{TR}=2084$, TI $=708$, $\mathrm{TE}=20 \mathrm{NEX} 2, \mathrm{FOV}=18 \mathrm{~cm}$, Matric $154 \times 256)$. An interleaved coronal series of $3.0-\mathrm{mm}$-thick sections was obtained with both beads centered, and a similar series of sagittal 3.0-mm-spaced sections was also acquired with one bead centered. The MRIs were developed onto x-ray film and scanned into Adobe Photoshop (Adobe Systems, San Jose, CA) on a Power Macintosh computer using a flatbed scanner (UMAX Powerlook II). The scanned MRI was then ported to the Canvas graphics program for stereotaxic analysis. The amygdala was outlined, and a 1-mm-spaced grid overlaid onto the MRI image (calibrated to marks on the x-ray film). For the coronal images, the grid was aligned with the midline; for the sagittal images, the grid was aligned with the glass bead.

Ibotenic acid injections. Ibotenic acid injections were planned to involve the entire amygdala. The coordinates for injection sites, which were typically separated from each other by $2 \mathrm{~mm}$, were measured from the grid superimposed on the MRI image. Before the lesion surgery, each monkey was anesthetized with ketamine hydrochloride $(8 \mathrm{mg} / \mathrm{kg})$, intubated with a tracheal cannula, and brought to a surgical level of anesthesia using isoflurane (1-2\%). Because of concerns for morbidity and mortality with one-stage lesions (i.e., lesioning both amygdalas on the same day), five of the six experimental animals received two-stage lesions of the amygdala. Intervals between the two surgeries ranged from 13 to $16 \mathrm{~d}$. Because all surgical sequelae, such as respiratory arrest and lethargy, were manageable through veterinary intervention, the sixth animal underwent bilateral amygdala injections. Recovery for this animal was similar to those receiving unilateral lesions. Throughout the surgery, the monkey's vital signs (heart rate, respiration, body temperature, $\mathrm{CO}_{2}$ levels, blood pressure, and blood oxygen levels) were monitored. A midline incision was made, the temporalis muscle was retracted, the fascia was reflected, and craniotomies were performed over the amygdala. The predicted dorsoventral location of the amygdala was verified electrophysiologically by making extracellular recordings using a tungsten microelectrode that was lowered into the amygdala along a trajectory estimated to be at a mid-rostrocaudal and mediolateral position within the amygdala. As the electrode was advanced through the amygdala, the coordinates of salient features such as the appearance of large, bursting cells (typically observed in the magnocellular division of the basal nucleus), fibers just ventral to the amygdala (the portion of the external capsule separating the amygdala from the entorhinal cortex), and the bottom of the brain were noted. These coordinates were used to adjust the coordinates determined from the MRIs. Typically, alterations in the coordinates that were caused by shifts in the brain when the dura was opened and cerebrospinal fluid was lost amounted to $1 \mathrm{~mm}$ or less.

Once the dorsoventral position of the amygdala was defined, the electrode was withdrawn. Ibotenic acid injections then commenced using a $10 \mu$ l Hamilton syringe (26 gauge beveled needle). In the amygdala, 1.0 $\mu \mathrm{l}$ of ibotenic acid (Biosearch Technologies, Novato, CA) $(10 \mathrm{mg} / \mathrm{ml}$ in $0.1 \mathrm{M}$ phosphate buffer) was injected into each site. To allow diffusion of the ibotenic acid and to reduce potential tissue damage, the injections were made at a rate of $0.2 \mu \mathrm{l} / \mathrm{min}$. A complete unilateral amygdala lesion 
required injections at 20-24 sites, with two to three rostrocaudal levels, three mediolateral levels, and three or four dorsocaudal levels at each mediolateral level. The individualized matrix of injections was developed through analysis of the presurgical MRIs. In the sixth animal that received a one-stage bilateral lesion, the injections were performed using two identical Hamilton syringes to simultaneously inject ibotenic acid at the same location within each amygdala. The dura was replaced and in some cases sutured, the temporalis muscle tissue was repositioned and sutured, the craniotomy was filled with Gelfoam, and the wound was sutured in three layers.

Postoperative recovery. Postoperatively, the monkeys' vital signs and general condition were monitored continuously for $24 \mathrm{hr}$ by veterinary staff. Postsurgical recovery varied substantially from animal to animal. In all cases, complete recovery from anesthesia appeared to be prolonged by the neurotoxin. In some animals, recovery was so advanced by $2 \mathrm{hr}$ that the animal was returned to the observation cage. In other animals, postsurgical lethargy continued for $6 \mathrm{hr}$ or more and in two cases, the animal required postsurgical mechanical ventilation because of the lack of spontaneous breathing. Lesioned animals (hereafter referred to as A-IBO animals) were allowed to recover for $6-8$ weeks after the second lesion before any behavioral testing commenced.

\section{Tail-withdrawal testing}

A-IBO and control monkeys underwent a warm-water tail-withdrawal assay (Dykstra and Woods, 1986). The monkey's tail was inserted into a thermos flask containing water maintained at either a non-noxious temperature $\left(40^{\circ} \mathrm{C}\right)$ or a noxious temperature $\left(50,53\right.$, or $\left.55^{\circ} \mathrm{C}\right)$. Water maintained at a noxious temperature resulted in a withdrawal response, in which the monkey removed its tail from the thermos flask after a certain length of time. In the absence of drugs, the tail-withdrawal response remains consistent in terms of latency across multiple applications of the noxious stimulus (Dykstra and Woods, 1986; Vivian et al., 1998). Drugs such as opioids (Dykstra and Woods, 1986; Dourish et al., 1990; Walker et al., 1993) and cannabinoids (Vivian et al., 1998) dosedependently increase the latency for the tail-withdrawal response, indicating the production of antinociception.

Apparatus. A standard primate restraint chair equipped with arm restraints was used for this procedure. Each monkey was restrained loosely at the neck and arms, such that the monkey was in a seated position with its tail hanging freely. Adjacent to the restraint chair were controlled-temperature water baths maintained at the desired temperatures. Water taken from the bath was poured into the thermos flask. An experimenter held the base of the monkey's tail in one hand and placed the distal 4-6 inches of the tail into the thermos (held in the other hand). Another experimenter, standing nearby, used a stopwatch to measure the latency (to the nearest $0.1 \mathrm{sec}$ ) for the monkey to remove its tail from the thermos. The experimenter measuring the latency for withdrawal was blind as to the experimental status of the monkey.

Procedure. A-IBO and control monkeys underwent 5-8 d of chairadaptation sessions during which they became accustomed to sitting in the restraint chairs with their tails hanging freely. Beginning 1 week after the end of the chair-adaptation sessions, the monkeys underwent tailwithdrawal testing. Each monkey underwent two tail-withdrawal test sessions separated by a 6 week interval. One session involved collecting dose-effect data for morphine, and the other session involved collecting dose-effect data for the cannabinoid receptor agonist WIN55,212-2. On each of the test days, water maintained at noxious temperatures $(50$ or $55^{\circ} \mathrm{C}$ for morphine; 50 or $53^{\circ} \mathrm{C}$ for WIN55,212-2) was used to elicit tail-withdrawal responses, and water maintained at $40^{\circ} \mathrm{C}$ was used to ensure that the monkey's tail-withdrawal responses were specific to noxious temperatures. The latency for the monkey to remove its tail from the water was measured to the nearest $0.1 \mathrm{sec}$. In the presence of drug, a cutoff time of $12 \mathrm{sec}$ was imposed to prevent tissue damage to the tail. A water temperature of $53^{\circ} \mathrm{C}$ was used as the "high" noxious stimulus for WIN55,212-2 (instead of $55^{\circ} \mathrm{C}$, as was used with morphine) because this drug does not produce significant antinociception in rhesus monkeys when a tail stimulus of $55^{\circ} \mathrm{C}$ is used (Vivian et al., 1998).

On a particular test day, the first presentation of a stimulus constituted the control, or baseline, tail-withdrawal trial relating to that stimulus (i.e., in the absence of drug). After baseline tail-withdrawal latencies were determined for each water temperature in both A-IBO and control monkeys, a multiple-trial, cumulative dosing procedure was used to obtain a dose-effect curve for the drug being tested that day (morphine or WIN55,212-2). Each trial involved injecting a particular dose of the drug. After each injection, tail-withdrawal latencies were measured at all three water temperatures; the order of presentation of the temperatures was varied (i.e., counterbalanced) from one trial to the next. All injections were administered intramuscularly, with the cumulative dose for each drug increasing in $1 / 4$ or $1 / 2 \log$ unit steps (beginning with a dose of $0.1 \mathrm{mg} / \mathrm{kg}$ ) until control animals reached the cutoff latency for tail withdrawal. Drug injections were separated by $30 \mathrm{~min}$ for morphine and $60 \mathrm{~min}$ for WIN55,212-2. Tail-withdrawal testing for a particular drug dose occurred $\sim 25 \mathrm{~min}$ after an injection of morphine or $55 \mathrm{~min}$ after an injection of WIN55,212-2.

\section{Statistical analysis}

For each monkey, tail-withdrawal latencies collected at each drug dose were converted to percentage of maximum possible antinociceptive effect (\%MPE) using the following formula:

$$
\% M P E=\left(E-E_{\min }\right) \times 100 /\left(E_{\max }-E_{\min }\right) .
$$

The baseline tail-withdrawal latency at a particular water temperature was used as $E_{\min }$, and $E_{\max }$ was 12 (a cutoff latency of $12 \mathrm{sec}$ was used for all experiments). Log dose-effect curves were constructed using leastsquares linear regression. $\mathrm{MPE}_{50}$ values (dose of drug resulting in $50 \%$ of the maximum possible antinociceptive effect) plus $95 \%$ confidence intervals $\left(\mathrm{CI}_{95 \%}\right)$ were calculated for the dose-effect curves where appropriate, using formulas provided by Tallarida and Murray (1987). The data were analyzed further using two-factor repeated measures ANOVA.

\section{Histology}

Initial preparation. After completion of all behavioral testing, all A-IBO subjects were preanesthetized with ketamine $\mathrm{HCl}(8 \mathrm{mg} / \mathrm{kg})$, deeply anesthetized with Nembutal $(50-100 \mathrm{mg} / \mathrm{kg}$, i.v.), and perfused intracardially. Perfusates included $4 \%$ paraformaldehyde in $0.1 \mathrm{M}$ sodium phosphate buffer, (pH 7.2), at $4^{\circ} \mathrm{C}, 250 \mathrm{ml} / \mathrm{min}$ for $10 \mathrm{~min}$ and $100 \mathrm{ml} / \mathrm{min}$ for $50 \mathrm{~min}$. Then, the brain was blocked stereotaxically, removed from the skull, and post-fixed for $6 \mathrm{hr}$ in the same fixative as the perfusate. The brain was cryoprotected in a solution containing $10 \%$ glycerol and $2 \%$ dimethylsulfoxide (DMSO) overnight, followed by a solution containing $20 \%$ glycerol and $2 \%$ DMSO for $3 \mathrm{~d}$. The brain was frozen using the isopentane method (described by Rosene et al., 1986) and stored at $-70^{\circ} \mathrm{C}$ until cut. Frozen sections were cut on a sliding microtome in the coronal plane at a thickness of $30 \mu \mathrm{m}$ (1-in-8 series) and placed into a cryoprotectant tissue collecting solution (TCS) (30\% ethylene glycol, $25 \%$ glycerin in $0.005 \mathrm{~m}$ sodium-phosphate buffer). The sections were stored at $-20^{\circ} \mathrm{C}$ until they were processed for Nissl staining. A 1 -in-8 series of sections was mounted onto gelatin-coated slides and stained with thionin.

Lesion analysis. To quantitatively evaluate the extent of the amygdala lesions, the volumes of the entire amygdala and of the lateral, basal, accessory basal, and central nuclei were measured in the left hemisphere of five rhesus monkeys of approximately the same age and weight as the A-IBO animals. Sections from these animals were kindly provided by Dr. Peter Rapp (Mount Sinai School of Medicine, New York, NY). Although the brains of these control animals were fixed and processed in a similar way, there were two differences. First, the brain was not blocked in the coronal plane but at an angle of $13^{\circ}$ so as to cut sections more perpendicular to the longitudinal plane of the hippocampus. Second, sections were cut at a thickness of $40 \mu \mathrm{m}$ rather than $30 \mu \mathrm{m}$ and the series was 1 -in-10 rather than 1-in-8. Because sections were measured throughout the full rostrocaudal extent of the amygdala and cross-sectional areas were multiplied by the appropriate rostrocaudal distance that they represented, these histological processing differences should not markedly affect our estimate of amygdaloid volumes.

For each control and experimental case, drawings were made of each section that contained the amygdaloid complex using a Leica stereomicroscope and camera lucida. The cross-sectional areas of the entire amygdala and the lateral, basal, accessory basal, and central nuclei were digitized using a SummaSketch II digitizing tablet connected to a PC with SigmaScan software. To compute the volumes, the cross-sectional areas were multiplied by the distance represented by each coronal section (240 $\mu \mathrm{m}$ for the A-IBO animals and $400 \mu \mathrm{m}$ for the control animals).

\section{RESULTS \\ Histology}

A complete description of the extent of ibotenic acid-induced damage with photomicrographic documentation for each of the 
experimental animals has been presented in Emery et al. (2001). We shall present a short summary of these data and the interested reader is referred to that earlier paper for more details. Microinjection of ibotenic acid into the amygdaloid complex produced a loss of neuronal cell profiles and proliferation of small glial cells (Fig. 1). The volume (cubic millimeters) of total amygdala (AMYG), individual amygdala nuclei [lateral (L), basal (B), accessory basal (AB), and central (Ce) nuclei], and entorhinal cortex (EC) in five normal unlesioned control animals versus the six A-IBO animals is shown in Tables 1 and 2. An estimate of the percentage volume of the total amygdala, of individual amygdala nuclei, and of entorhinal cortex damaged bilaterally in the A-IBO animals is shown in Table 3. All six A-IBO animals sustained large lesions of the amygdaloid complex bilaterally. In terms of damage to individual nuclei, the lateral and basal nuclei sustained the heaviest damage (73-100\% of the lateral nucleus damaged; $70-100 \%$ of the basal nucleus damaged), followed by the accessory basal nucleus (45-100\% of the nucleus damaged). The central nucleus sustained the least amount of damage in the A-IBO animals, with a damage range of 47-90\%. EC damage was observed just below the amygdala; levels caudal to the amygdala were intact. It is important to point out, that only area 35 of the perirhinal cortex consistently demonstrated bilateral damage and that this occurred only ventral to the amygdaloid complex. The portions of area 35 located rostral and caudal to the amygdala were largely intact.

\section{Antinociception}

\section{Morphine}

In the absence of morphine, neither control animals nor A-IBO animals withdrew their tails from $40^{\circ} \mathrm{C}$ (non-noxious) water. When the temperature of the water was raised to noxious levels $\left(50\right.$ or $55^{\circ} \mathrm{C}$ ), however, monkeys displayed a characteristic tailwithdrawal response. At both noxious water temperatures tested, baseline tail-withdrawal latencies of A-IBO animals were not significantly different from those of control animals $\left(50^{\circ} \mathrm{C}\right.$ : control, $3.38 \pm 1.09$; A-IBO, $4.72 \pm 0.29 ; 55^{\circ} \mathrm{C}$ : control, $1.37 \pm 0.33$; A-IBO, $2.67 \pm 0.79$; Student's $t$ test; $p>0.05)$. This is important because it indicates that the amygdala lesions did not change the sensitivity of the animals to thermal stimulation.

Morphine dose-effect curves for control animals and A-IBO animals are shown in Figure 2. Morphine produced dosedependent antinociception in control animals regardless of whether $50^{\circ} \mathrm{C}$ water (Fig. $2 A ; \mathrm{MPE}_{50}, 0.85 \mathrm{mg} / \mathrm{kg} ; \mathrm{CI}_{95}, 0.35-$ 2.05 ) or $55^{\circ} \mathrm{C}$ water (Fig. $2 B$; $\mathrm{MPE}_{50}, 1.06 \mathrm{mg} / \mathrm{kg}, \mathrm{CI}_{95}, 0.02-46.2$ ) was used as the noxious stimulus. At both water temperatures, administration of naltrexone $(10 \mathrm{mg} / \mathrm{kg}$, i.m.) completely reversed morphine antinociception (Fig. $2 A, B$ ). In A-IBO animals, however, morphine produced less antinociception as compared with control monkeys (Fig. 2). With the $50^{\circ} \mathrm{C}$ stimulus, there was a trend toward a reduction in morphine antinociception, but the reduction did not reach statistical significance (Fig. $2 A$; twofactor ANOVA; $\left.F_{(1,10)}=2.3375 ; p>0.05\right)$; with the $55^{\circ} \mathrm{C}$ stimulus, however, the reduction in morphine antinociception in A-IBO animals did reach statistical significance as compared with control animals (Fig. $2 B$; two-factor ANOVA; $F_{(1,10)}=7.782 ; p<$ 0.05 , significant main effect of lesion).

\section{WIN55,212-2}

In the absence of WIN55,212-2, neither control animals nor A-IBO animals withdrew their tails from $40^{\circ} \mathrm{C}$ (non-noxious) water. When the temperature of the water was raised to noxious levels $\left(50\right.$ or $\left.53^{\circ} \mathrm{C}\right)$, however, monkeys displayed a characteristic tail-withdrawal response. At both noxious water temperatures tested, the baseline tail-withdrawal latencies of A-IBO animals were not significantly different from those of control animals $\left(50^{\circ} \mathrm{C}\right.$ : control, $2.75 \pm 0.22 ; \mathrm{A}-\mathrm{IBO}, 2.66 \pm 0.47 ; 53^{\circ} \mathrm{C}$ : control, $1.73 \pm 0.32$; A-IBO, $1.52 \pm 0.4$; Student's $t$ test; $p>0.05)$.

WIN55,212-2 dose-effect curves for control animals and A-IBO animals are shown in Figure 3. WIN55,212-2 produced a dose-dependent antinociception in control animals regardless of whether $50^{\circ} \mathrm{C}$ water (Fig. $3 A$ ) or $53^{\circ} \mathrm{C}$ water (Fig. $3 B ; \mathrm{MPE}_{50}$, $\left.0.1942 \mathrm{mg} / \mathrm{kg} ; \mathrm{CI}_{95}, 0.102-0.367\right)$ was used as the noxious stimulus $\left(\mathrm{MPE}_{50}\right.$ and confidence intervals were not calculated for the $50^{\circ} \mathrm{C}$ stimulus because all animals displayed close to maximal antinociception at this stimulus after administration of the second dose of WIN55,212-2; see Fig. 3A). At both water temperatures, administration of the CB1 receptor antagonist SR141716A (5.6 $\mathrm{mg} / \mathrm{kg}$, i.m.) completely reversed WIN55,212-2-induced antinociception (Fig. $3 A, B$ ). In A-IBO animals, however, WIN55,212-2 produced less antinociception as compared with control monkeys (Fig. 3). Although the antinociceptive effect of morphine was not significantly reduced at $50^{\circ} \mathrm{C}$ in A-IBO animals (Fig. $2 A$ ), the antinociceptive effect of WIN55,212-2 was significantly reduced when this stimulus temperature was used (Fig. $3 A$; two-factor ANOVA; $F_{(1,10)}=8.518 ; p<0.05$; significant main effect of lesion). The antinociceptive effect of WIN55,212-2 also was significantly reduced when the $53^{\circ} \mathrm{C}$ stimulus was used (Fig. $3 B$; two-factor ANOVA; $F_{(1,10)}=9.888 ; p<0.05$, significant main effect of lesion).

The results obtained with WIN55,212-2 parallel those obtained with morphine in that the antinociceptive effects of both drugs were significantly reduced in A-IBO animals as compared with control animals (compare Figs. 2, 3).

\section{DISCUSSION}

The present data indicate that the nonhuman primate amygdaloid complex contributes to antinociceptive processes. Systemically administered morphine produced dose-dependent antinociception in control monkeys (Fig. 2) in a manner similar to that shown previously (Dykstra and Woods, 1986; Dourish et al., 1990). The cannabinoid receptor agonist WIN55,212-2 also produced dosedependent antinociception in control monkeys (Fig. 3) in a manner similar to that reported by Vivian et al. (1998). In monkeys with bilateral lesions of the amygdaloid complex, however, the antinociceptive effect of each drug was significantly reduced (see Results and Figs. 2, 3). The reduction was stronger with lower versus higher drug doses (Figs. 2, 3).

Indeed, interpretation of these effects is confounded somewhat by the lack of sham operations in our control monkeys (monkeys that went on to be used in additional, unrelated studies). It is unlikely, however, that reduction of antinociception in the lesioned monkeys was a nonspecific effect relating to the stressful nature of invasive surgery. Baseline nociceptive reactivity was not different between control and lesioned monkeys (see Results), strongly suggesting that neither stress-induced hypoalgesia nor hyperalgesia was present in the lesioned monkeys.

\section{Relation to rodent studies}

The present studies are in general agreement with our previous studies conducted in the rat. These earlier studies indicated that excitotoxin-induced lesions of the amygdala reduce the antinociceptive effects of systemically administered morphine on a number of different pain assays (Manning and Mayer, 1995a,b; Man- 


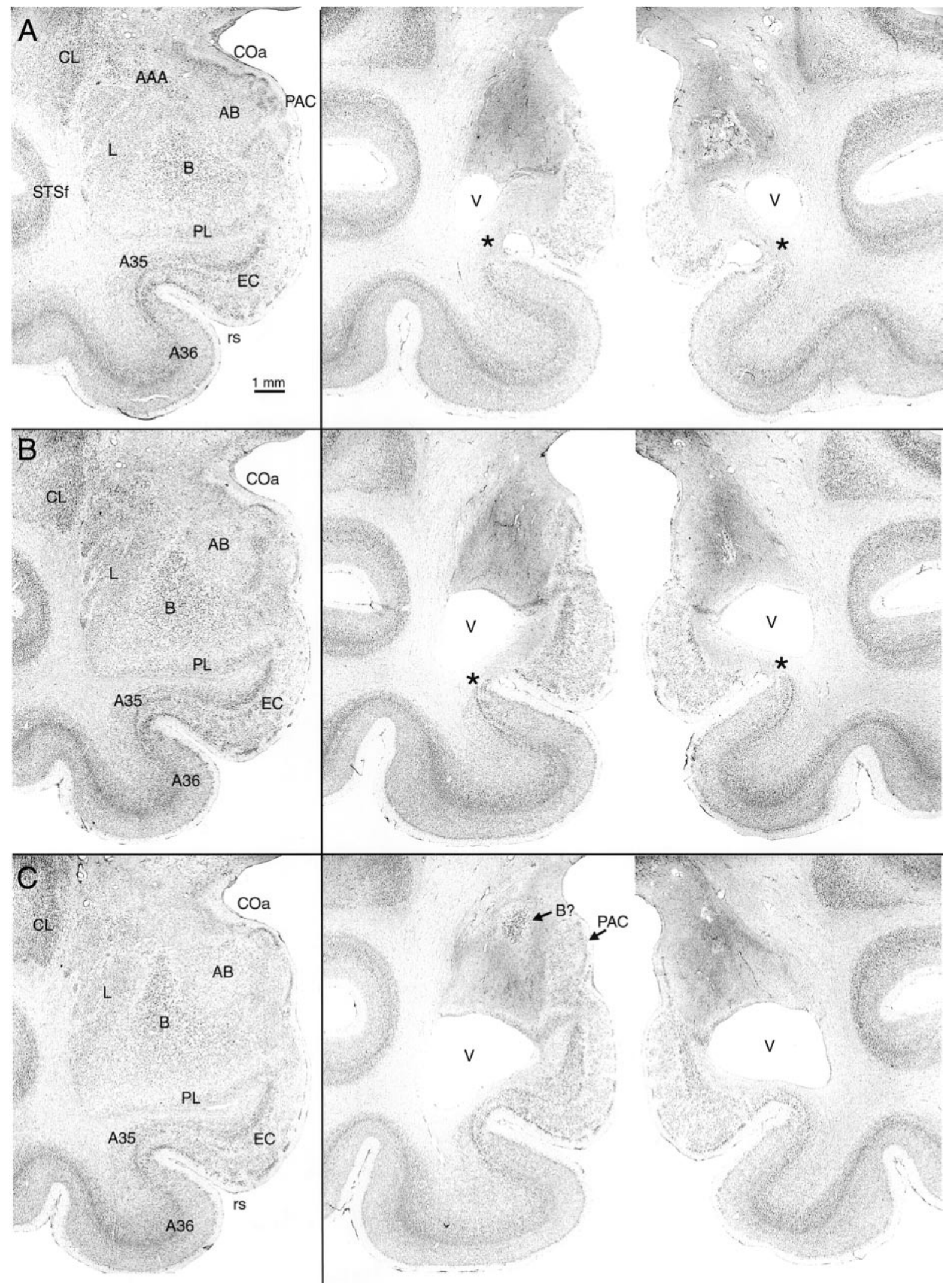

Figure 1. Photomicrographs of representative coronal sections through the rostrocaudal extent of the amygdaloid complex in a control monkey (left panels) and an ibotenic acid-lesioned (A-IBO) monkey (subject 25468; right panels). The sections are arranged from rostral $(A)$ to caudal $(C)$. Scale bar, $1 \mathrm{~mm}$ (applies to all panels). $A 35$, Area 35 of the perirhinal cortex; $A 36$, area 36 of the perirhinal cortex; $A A A$, anterior amygdaloid area; $A B$, accessory basal nucleus of the amygdala; $B$, basal nucleus of the amygdala; $C L$, claustrum; $C O a$, anterior cortical nucleus of the amygdala; $E C$, entorhinal cortex; $L$, lateral nucleus of the amygdala; $P A C$, periamygdaloid cortex; $P L$, paralaminar nucleus of the amygdala; $r s$, rhinal sulcus; STSf, fundus of the superior temporal sulcus; $V$, ventricle. ${ }^{*}$ indicates damage in the fundus of the rhinal sulcus. 


\begin{tabular}{|c|c|c|c|c|c|c|}
\hline Subject ID & AMYG & $\mathrm{L}$ & B & $\mathrm{AB}$ & $\mathrm{Ce}$ & $\mathrm{EC}$ \\
\hline 24080 & 282.49 & 54.63 & 71.70 & 37.8 & 15.97 & 130.70 \\
\hline 25014 & 281.70 & 62.18 & 66.76 & 37.16 & 16.94 & 115.38 \\
\hline 24712 & 264.61 & 52.38 & 63.73 & 35.63 & 15.14 & 110.83 \\
\hline 25616 & 251.46 & 54.78 & 51.13 & 34.42 & 12.97 & 103.94 \\
\hline 24047 & 309.62 & 61.75 & 69.31 & 44.44 & 15.47 & 147.07 \\
\hline Mean & 277.98 & 57.15 & 64.53 & 37.89 & 15.30 & 121.58 \\
\hline
\end{tabular}

Volume (cubic millimeters) of total amygdala (AMYG), individual amygdala nuclei [lateral (L), basal (B), accessory basal (AB), and central (Ce) nuclei], and entorhinal cortex (EC) in five normal unlesioned control animals with similar histories to the experimental subjects and raised at the CRPRC. Only the left hemisphere was available for comparison.

ning, 1998). Importantly, a reduction in antinociception was observed in these studies only if a large proportion of neurons in the Ce was destroyed. Lesions centered on the basal and lateral nuclei of the amygdala were ineffective in reducing morphine antinociception. Interestingly, of the amygdaloid nuclei analyzed in the present study, the Ce suffered the least amount of damage after ibotenic acid injection (volume reduction, 47-84\%; Table 3 ). By contrast, the basal and lateral nuclei were much more extensively damaged (Table 3 ). It is possible that the damage inflicted on the $\mathrm{Ce}$, although not complete, was enough to produce the partial reduction in antinociception observed here. Furthermore, it is possible that had the lesions of the Ce been more complete, a stronger reduction in antinociception (e.g., at higher drug doses or with the lower intensity tail stimulus) would have been observed.

Alternatively, the present reductions in antinociception may be related to neuronal cell loss in amygdaloid areas outside the $\mathrm{Ce}$. Indeed, the literature contains some evidence that other amygdaloid areas contribute to antinociceptive processes. Studies in the anesthetized rat suggest that microinjection of $\mu$-opioid receptor agonists (morphine, DAMGO) into the basolateral amyg- daloid complex is capable of eliciting antinociception (Helmstetter et al., 1993; Tershner and Helmstetter, 2000). Although our own studies in the rat suggest that amygdaloid areas adjacent to the $\mathrm{Ce}$ are not critical contributors to the antinociceptive effect of systemically administered morphine (Manning and Mayer, 1995a,b; Manning, 1998), the present results do not rule out a contribution of these areas to morphine-induced and/or cannabinoid-induced antinociception in the primate.

It is important to point out that the primate amygdaloid complex is heavily interconnected with a variety of unimodal and polymodal sensory cortical areas in the nonhuman primate (Amaral and Price, 1984; Amaral et al., 1994; Stefanacci and Amaral, 2000). This information is ultimately conveyed to the $\mathrm{Ce}$ through intrinsic connections that involve both the lateral and basal nuclei. Thus, in higher primates and humans, antinociception that is related to perception of fearful stimuli (see below) would undoubtedly rely on the activation of the Ce by the nuclei that were more substantially damaged in the current studies. One might speculate that although the Ce may not have been totally eliminated in the current studies, the drastic deafferentation that was produced may have led substantially to its dysfunction. The effects of more complete and selective damage to the amygdaloid complex will be evaluated in future studies.

\section{Analgesic processes in humans and nonhuman primates}

Although numerous studies have reported on the antinociceptive/ analgesic effects of various drugs in primates (Craft and Dykstra, 1992; Walker et al., 1993; Vivian et al., 1998) and humans (Burril et al., 1944; Hill et al., 1952; Wolff et al., 1966; Dundee et al., 1973; Yang et al., 1979; Price et al., 1985; Cooper et al., 1986; Chapman et al., 1990; Hogger and Rohdewald, 1999), few studies have addressed the brain areas and neural circuitry underlying these effects. The classic experiments of Pert and colleagues (Pert and Yaksh, 1974; Pert and Maxey, 1975) provided the first indication of brain circuitry acted on by morphine to produce antinociception in the primate. These investigators demonstrated that

Table 2. Volume of AMYG, individual amygdala nuclei, and EC in A-IBO lesion group

\begin{tabular}{|c|c|c|c|c|c|c|c|c|c|c|c|c|}
\hline Subject ID & AMYG (L) & AMYG (R) & $\mathrm{L}(\mathrm{L})$ & $\mathrm{L}(\mathrm{R})$ & B (L) & $\mathrm{B}(\mathrm{R})$ & $\mathrm{AB}(\mathrm{L})$ & $\mathrm{AB}(\mathrm{R})$ & $\mathrm{Ce}(\mathrm{L})$ & $\mathrm{Ce}(\mathrm{R})$ & $\mathrm{EC}(\mathrm{L})$ & $\mathrm{EC}(\mathrm{R})$ \\
\hline 26085 & 46.51 & 42.50 & 0.85 & 0 & 1.82 & 0.40 & 2.67 & 2.03 & 6.18 & 5.29 & 33.10 & 57.70 \\
\hline 25468 & 67.75 & 34.16 & 3.90 & 0.28 & 3.09 & 0 & 7.19 & 0.16 & 6.20 & 2.38 & 83.56 & 83.54 \\
\hline 24349 & 107.88 & 28.70 & 11.95 & 0 & 14.29 & 0 & 19.08 & 0 & 8.24 & 4.89 & 49.27 & 40.67 \\
\hline 25627 & 78.23 & 54.71 & 0.85 & 4.27 & 1.84 & 2.06 & 15.82 & 4.15 & 7.97 & 5.56 & 57.31 & 66.56 \\
\hline 25571 & 12.50 & 82.35 & 0 & 6.20 & 0 & 6.26 & 0 & 11.29 & 1.40 & 3.69 & 49.89 & \\
\hline 25942 & 73.35 & 113.17 & 3.16 & 14.93 & 3.59 & 19.43 & 12.89 & 20.76 & 6.09 & 5.92 & 60.16 & 77.91 \\
\hline
\end{tabular}

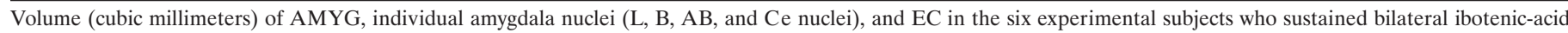
lesions of the amygdala [both left (L) and right (R) sides are displayed].

\begin{tabular}{|c|c|c|c|c|c|c|c|c|c|c|c|c|}
\hline Subject ID & AMYG (L) & AMYG (R) & $\mathrm{L}(\mathrm{L})$ & $\mathrm{L}(\mathrm{R})$ & $\mathrm{B}(\mathrm{L})$ & $\mathrm{B}(\mathrm{R})$ & $\mathrm{AB}(\mathrm{L})$ & $\mathrm{AB}(\mathrm{R})$ & $\mathrm{Ce}(\mathrm{L})$ & $\mathrm{Ce}(\mathrm{R})$ & $\mathrm{EC}(\mathrm{L})$ & $\mathrm{EC}(\mathrm{R})$ \\
\hline 26085 & 83.27 & 84.71 & 98.51 & 100 & 97.18 & 99.38 & 92.95 & 94.64 & 59.61 & 65.42 & 72.78 & 52.54 \\
\hline 25468 & 75.63 & 87.71 & 93.18 & 99.51 & 95.21 & 100 & 81.02 & 99.58 & 59.48 & 84.44 & 31.13 & 31.29 \\
\hline 24349 & 61.19 & 89.68 & 79.09 & 100 & 77.86 & 100 & 49.64 & 100 & 46.14 & 68.04 & 59.48 & 59.48 \\
\hline 25627 & 71.86 & 80.32 & 98.51 & 92.53 & 97.15 & 96.81 & 58.25 & 89.05 & 47.91 & 63.66 & 52.86 & 45.26 \\
\hline 25571 & 95.50 & 70.38 & 100 & 89.15 & 100 & 90.30 & 100 & 70.20 & 90.85 & 75.88 & 58.97 & \\
\hline 25942 & 73.61 & 59.29 & 94.47 & 73.88 & 94.44 & 69.98 & 65.98 & 45.51 & 60.20 & 61.31 & 50.52 & 35.92 \\
\hline
\end{tabular}

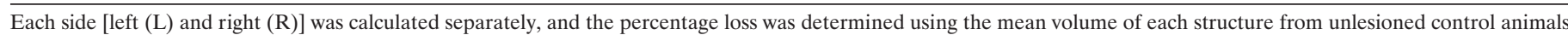
$(n=5)$. 


\section{A) $50^{\circ} \mathrm{C}$ Tail Stimulus}

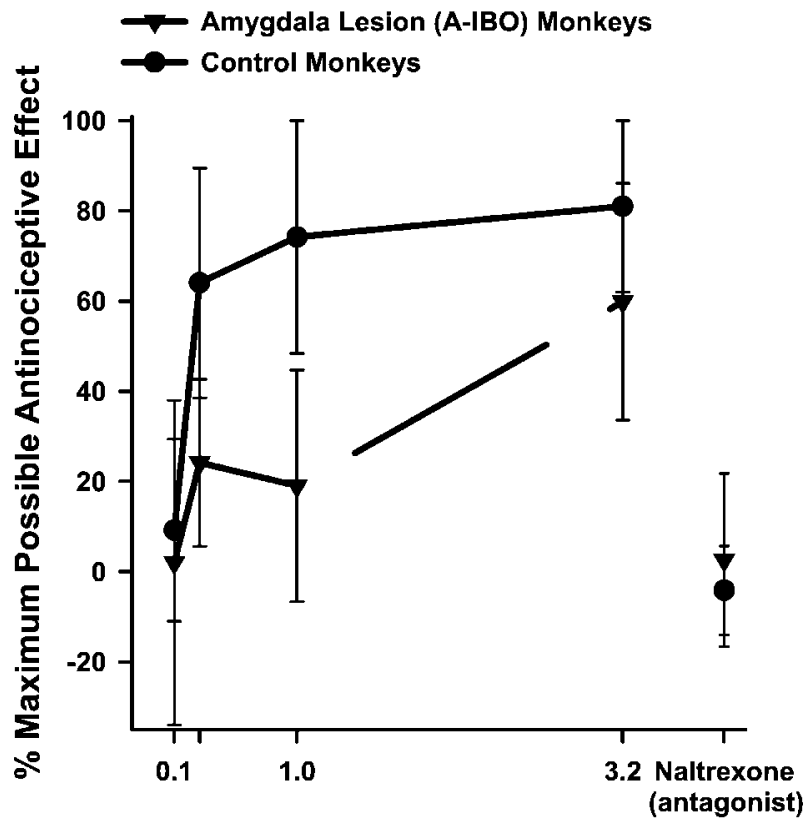

B) $55^{\circ} \mathrm{C}$ Tail Stimulus

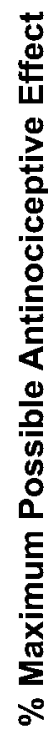

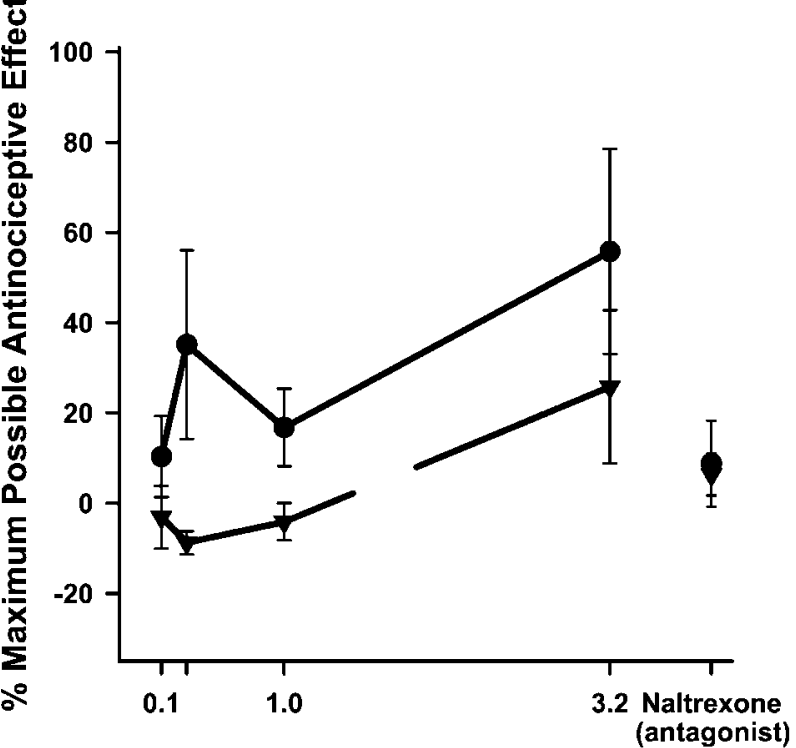

Cumulative Morphine Dose (mg/kg)

Figure 2. Dose-effect relations for morphine in monkeys with bilateral amygdala lesions (A-IBO monkeys; $n=6$ ) versus unoperated control monkeys. Dose-effect data were obtained for two different noxious stimuli applied to the tail $\left(A, 50^{\circ} \mathrm{C}\right.$ water; $B, 55^{\circ} \mathrm{C}$ water $)$. Raw data were converted to $\% \mathrm{MPE}$ scores using the formula provided in Materials and Methods.

microinjection of morphine into periaqueductal and periventricular regions of the midbrain and thalamus in rhesus monkeys produced antinociception as measured on the shock titration paradigm. Although later studies performed in both humans (Hosobuchi et al., 1977; Richardson and Akil, 1977; Gybels and Kupers, 1990) and monkeys (Gerhart et al., 1984; Lin et al., 1994) confirmed the ability of PAG neurons to elicit antinociception in

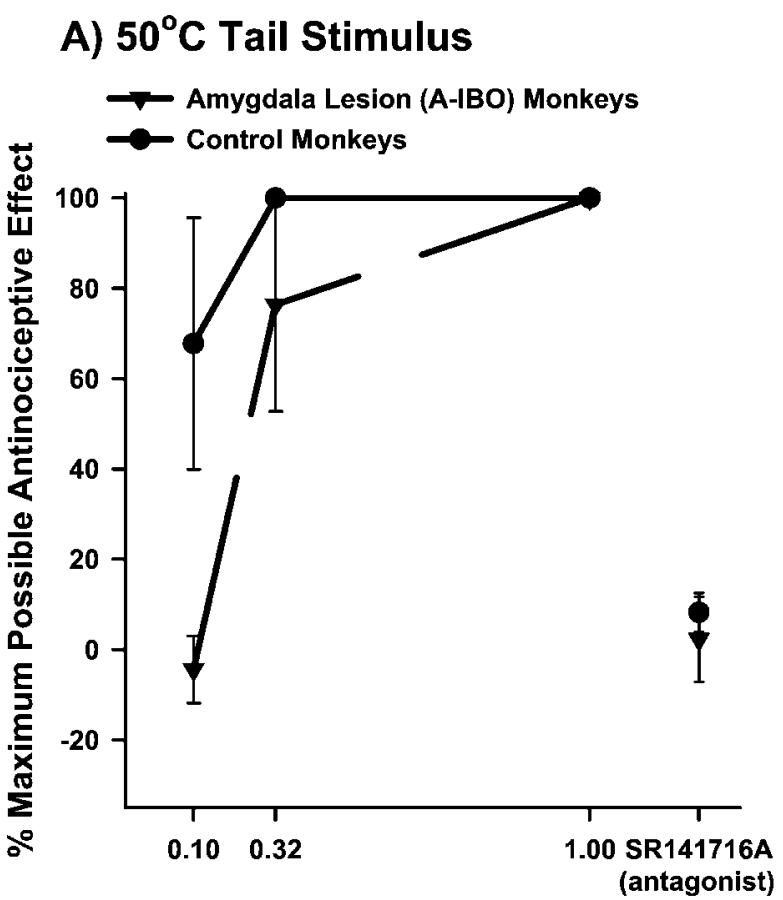

\section{B) $53^{\circ} \mathrm{C}$ Tail Stimulus}

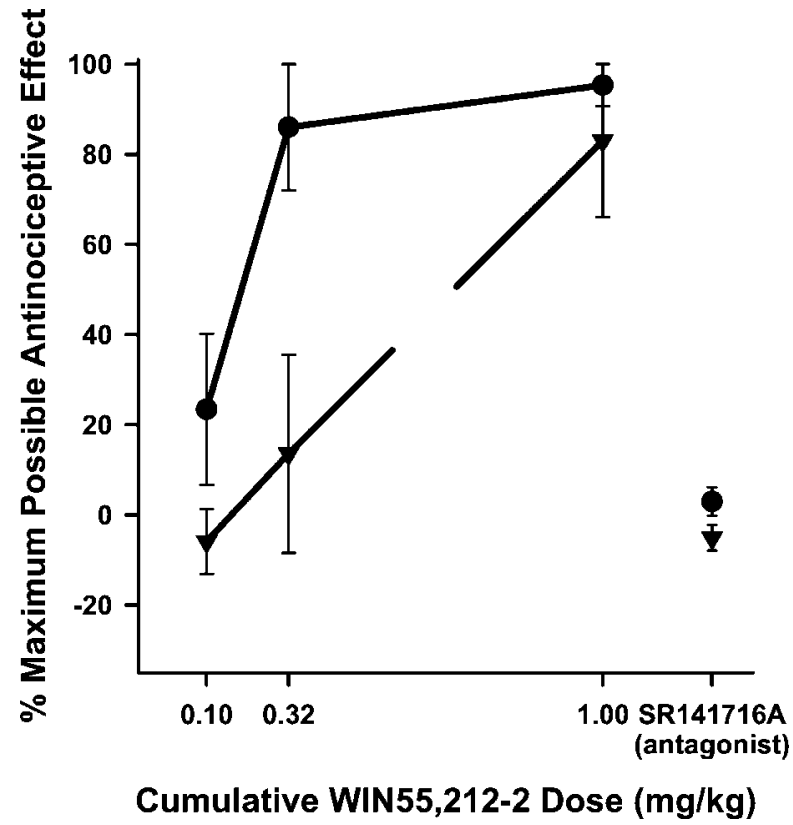

Figure 3. Dose-effect relations for the cannabinoid receptor agonist WIN55,212-2 in monkeys with bilateral amygdala lesions (A-IBO monkeys; $n=6$ ) versus unoperated control monkeys. Dose-effect data were obtained for two different noxious stimuli applied to the tail $\left(A, 50^{\circ} \mathrm{C}\right.$ water; $B, 53^{\circ} \mathrm{C}$ water). Raw data were converted to $\% \mathrm{MPE}$ scores using the formula provided in Materials and Methods.

higher mammals, no attempt was made to link, in a causal fashion, neuronal activity in this region with the pain-killing effects of systemically administered morphine (e.g., using lesion techniques).

In more recent years, functional neuroimaging techniques such as positron emission tomography and functional magnetic resonance imaging have provided novel, albeit correlative, insights 
regarding the contribution of thalamic and cerebral cortical areas to the processing of nociceptive input in humans (Talbot et al., 1991; Rainville et al., 1997). Regarding pain-modulating circuitry and analgesic drug action, however, limited data are available. A few studies have correlated changes in regional brain activity [as inferred from changes in regional cerebral blood flow (rCBF)] with various analgesic manipulations, including electrical stimulation of the "somatosensory thalamus" (Duncan et al., 1998), electrical stimulation of the precentral gyrus (i.e., motor cortex) (Peyron et al., 1995; Garcia-Larrea et al., 1999), or systemic administration of the opioid fentanyl (Adler et al., 1997; Casey et al., 2000). Although the analgesia produced by these manipulations is correlated with increases in $\mathrm{rCBF}$ in areas such as the anterior cingulate cortex, anterior insular cortex, and prefrontal cortex, it is difficult to draw strong conclusions regarding analgesic mechanisms in humans on the basis of these correlative data alone.

In the context of previous studies of humans and nonhuman primates, then, the present results are notable as the first demonstrating the necessity of a specific brain region for the full expression of opioid- and cannabinoid-induced antinociception in the primate.

\section{Overlap in neural circuitry activated by opioids and cannabinoids}

The present results add to a growing body of evidence indicating that cannabinoids produce antinociception through similar painmodulating circuits as those acted on by opioids. In terms of distribution of receptors, the brains of rodents and primates contain an abundance of both $\mu$-opioid and cannabinoid CB1 receptors in regions, such as the amygdala, PAG, and RVM, that are linked to pain-modulation (Mansour et al., 1995; Ding et al., 1996; Pettit et al., 1998; Schulz et al., 1998; Ong and Mackie, 1999). Like opioids, cannabinoids elicit antinociception when microinjected into the PAG (Martin et al., 1995) or RVM (Martin et al., 1998), albeit via a CB1 receptor-mediated mechanism rather than an opioid receptor-mediated mechanism. Furthermore, like morphine-induced antinociception, cannabinoid-induced antinociception is reduced by inactivation of RVM neurons and is correlated with activation of a class of pain-modulating neurons in the RVM referred to as the OFF cell (Meng et al., 1998). These results, coupled with the present results, indicate that the antinociceptive effects of cannabinoids, like those of opioids, derive in part from actions on a pain-modulating circuit that includes the amygdala, PAG, and RVM (Manning, 1998).

\section{Fear, antinociception, and the amygdala}

There is an extensive literature implicating the amygdala in emotional and social information processing (Aggleton, 1993; LeDoux, 1995; Davis, 1998; Emery and Amaral, 2000). The amygdala appears to be involved in inhibiting approach behavior while evaluating animate and inanimate environmental stimuli as potential threats. Once the evaluation has been made that a threat is present, the amygdala also is involved in coordinating an appropriate species-specific response. The amygdala is capable of these functions because of an extensive network of connections with brain regions ranging from the hypothalamus and brainstem to the striatum, hippocampal formation, and neocortex (Amaral et al., 1992). Interestingly, a component of the overall reaction to a fear-inducing stimulus includes antinociception; i.e., in a threatening environmental situation, an animal's perception of a painful stimulus is reduced so that its full attention can be directed toward engagement of defense reactions. Rodent studies have shown that fear-induced antinociception is dependent on an intact amygdala (Helmstetter, 1992; Helmstetter and Bellgowan, 1993) and is likely mediated by a direct projection from the Ce to the PAG (Bellgowan and Helmstetter, 1996). Indeed, the psychological state of fear is accompanied by antinociception in humans (Rhudy and Meagher, 2000) and likely involves the transmission of information relating to a threatening stimulus from neocortical sensory areas to the amygdala and resultant activation of the subcortical projections of the amygdala via the Ce. This evidence, coupled with our present and previous results (Manning and Mayer, 1995a,b; Manning, 1998), suggests the possibility that systemically administered opioids, although not producing a state of fear as such, produce part of their pain-killing effects in humans by interacting with amygdaloid circuitry that is normally activated during the state of fear under drug-free conditions.

\section{REFERENCES}

Adler LJ, Gyulai FE, Diehl DJ, Mintun MA, Winter PM, Firestone LL (1997) Regional brain activity changes associated with fentanyl analgesia elucidated by positron emission tomography. Anesth Analg [Erratum (1997) 84:949] 84:120-126.

Aggleton JP (1993) The contribution of the amygdala to normal and abnormal emotional states. Trends Neurosci 16:328-333.

Alvarez-Royo P, Clower RP, Zola-Morgan S, Squire LR (1991) Stereotaxic lesions of the hippocampus in monkeys: determination of surgical coordinates and analysis of lesions using magnetic resonance imaging. J Neurosci Methods 38:223-232.

Amaral DG, Price JL (1984) Amygdalo-cortical projections in the monkey (Macaca fascicularis). J Comp Neurol 230:465-496.

Amaral DG, Price JL, Pitkanen A, Carmichael ST (1992) Anatomical organization of the primate amygdaloid complex. In: The amygdala: neurobiological aspects of emotion, memory, and mental dysfunction (Aggleton JP, ed), pp 1-66. New York: Wiley.

Bellgowan PS, Helmstetter FJ (1996) Neural systems for the expression of hypoalgesia during nonassociative fear. Behav Neurosci 110:727-736.

Bernard JF, Huang GF, Besson JM (1992) Nucleus centralis of the amygdala and the globus pallidus ventralis: electrophysiological evidence for an involvement in pain processes. J Neurophysiol 68:551-569.

Bitner RS, Nikkel AL, Curzon P, Arneric SP, Bannon AW, Decker MW (1998) Role of the nucleus raphe magnus in antinociception produced by ABT- 594: immediate early gene responses possibly linked to neuronal nicotinic acetylcholine receptors on serotonergic neurons. J Neurosci 18:5426-5432.

Burkey AR, Carstens E, Wenniger JJ, Tang J, Jasmin L (1996) An opioidergic cortical antinociception triggering site in the agranular insular cortex of the rat that contributes to morphine antinociception. J Neurosci 16:6612-6623.

Burril DY, Goetzl FR, Ivy AC (1944) The pain threshold raising effect of amphetamine. J Dent Res 23:337-344.

Casey KL, Svensson P, Morrow TJ, Raz J, Jone C, Minoshima S (2000) Selective opiate modulation of nociceptive processing in the human brain. J Neurophysiol 84:525-533.

Chapman CR, Hill HF, Seager L, Gavrin J (1990) Profiles of opioid analgesia in humans after intravenous bolus administration: alfentanil, fentanyl and morphine compared on experimental pain. Pain 43:47-55.

Cooper BY, Vierck Jr CJ, Yeomans DC (1986) Selective reduction of second pain sensations by systemic morphine in humans. Pain 24:93-116.

Craft RM, Dykstra LA (1992) Agonist and antagonist activity of kappa opioids in the squirrel monkey. I. Antinociception and urine output. J Pharmacol Exp Ther 260:327-333.

Davis M (1998) Are different parts of the extended amygdala involved in fear versus anxiety? Biol Psychiatry 44:1239-1247.

Ding YQ, Kaneko T, Nomura S, Mizuno N (1996) Immunohistochemical localization of mu-opioid receptors in the central nervous system of the rat. J Comp Neurol 367:375-402.

Dourish CT, O'Neill MF, Schaffer LW, Siegl PK, Iversen SD (1990) The cholecystokinin receptor antagonist devazepide enhances morphine-induced analgesia but not morphine-induced respiratory depression in the squirrel monkey. J Pharmacol Exp Ther 255:1158-1165.

Duncan GH, Kupers RC, Marchand S, Villemure JG, Gybels JM, Bushnell MC (1998) Stimulation of human thalamus for pain relief: possible modulatory circuits revealed by positron emission tomography. J Neurophysiol 80:3326-3330.

Dundee JW, Gupta PK, Jones CJ (1973) Modification of the analgesic action of pethidine and morphine by three opiate antagonists, a respi- 
ratory stimulant (doxapram) and an analeptic (nikethamide); a study using experimental pain stimulus in man. Br J Pharmacol 48:326.

Dykstra LA, Woods JH (1986) A tail withdrawal procedure for assessing analgesic activity in rhesus monkeys. J Pharmacol Methods 15:263-269.

Emery NJ, Amaral DG (2000) The role of the amygdala in primate social cognition. In: Cognitive neuroscience of emotion (Lane RD, Nadel L, eds), pp 156-191. New York: Oxford UP.

Emery NJ, Capitanio JP, Mason WA, Machado CJ, Mendoza SP, Amaral DG (2001) The effects of bilateral lesions of the amygdala on dyadic social interactions in rhesus monkeys (Macaca mulatta). Behav Neurosci 115:515-544.

Fields HL, Basbaum AI (1999) Central nervous system mechanisms of pain modulation. In: Textbook of pain (Wall PD, Melzack R, eds), pp 243-257. Edinburgh: Churchill Livingstone.

Garcia-Larrea L, Peyron R, Mertens P, Gregoire MC, Lavenne F, Le Bars D, Convers P, Mauguiere F, Sindou M, Laurent B (1999) Electrical stimulation of motor cortex for pain control: a combined PETscan and electrophysiological study. Pain 83:259-273.

Gerhart KD, Yezierski RP, Wilcox TK, Willis WD (1984) Inhibition of primate spinothalamic tract neurons by stimulation in periaqueductal gray or adjacent midbrain reticular formation. $J$ Neurophysiol 51:450-466.

Gybels J, Kupers R (1990) Deep brain stimulation in the treatment of chronic pain in man: where and why? Neurophysiol Clin 20:389-398.

Helmstetter FJ (1992) The amygdala is essential for the expression of conditional hypoalgesia. Behav Neurosci 106:518-528.

Helmstetter FJ, Bellgowan PS (1993) Lesions of the amygdala block conditional hypoalgesia on the tail flick test. Brain Res 612:253-257.

Helmstetter FJ, Bellgowan PS, Tershner SA (1993) Inhibition of the tail flick reflex following microinjection of morphine into the amygdala. NeuroReport 4:471-474.

Hill HE, Kornetsky CH, Flanary HG, Wikler A (1952) Effects of anxiety and morphine on discrimination of intensities of painful stimuli. J Clin Invest 31:473-480.

Hirakawa N, Tershner SA, Fields HL, Manning BH (2000) Bidirectional changes in affective state elicited by manipulation of medullary pain-modulatory circuitry. Neuroscience 100:861-871.

Hogger P, Rohdewald P (1999) Comparison of tilidine/naloxone, tramadol and bromfenac in experimental pain: a double-blind randomized crossover study in healthy human volunteers. Int J Clin Pharmacol Ther 37:377-385.

Holland PC, Gallagher M (1999) Amygdala circuitry in attentional and representational processes. Trends Cogn Sci 3:65-73.

Hosobuchi Y, Adams JE, Linchitz R (1977) Pain relief by electrical stimulation of the central gray matter in humans and its reversal by naloxone. Science 197:183-186.

LeDoux JE (1995) Emotion: clues from the brain. Annu Rev Psychol 46:209-235.

Lin Q, Peng Y, Willis WD (1994) Glycine and GABAA antagonists reduce the inhibition of primate spinothalamic tract neurons produced by stimulation in periaqueductal gray. Brain Res 654:286-302.

Manning BH (1998) A lateralized deficit in morphine antinociception after unilateral inactivation of the central amygdala. J Neurosci 18:9453-9470.

Manning BH, Franklin KBJ (1998) Morphine analgesia in the formalin test: reversal by microinjection of quaternary naloxone into the posterior hypothalamic area or periaqueductal gray. Behav Brain Res 92:97-102.

Manning BH, Mayer DJ (1995a) The central nucleus of the amygdala contributes to the production of morphine antinociception in the formalin test. Pain 63:141-152.

Manning BH, Mayer DJ (1995b) The central nucleus of the amygdala contributes to the production of morphine antinociception in the rat tail-flick test. J Neurosci 15:8199-8213.

Manning BH, Morgan MJ, Franklin K (1994) Morphine analgesia in the formalin test: evidence for forebrain and midbrain sites of action. Neuroscience 63:289-294.

Mansour A, Fox CA, Burke S, Akil H, Watson SJ (1995) Immunohistochemical localization of the cloned $\mu$ opioid receptor in the rat CNS. J Chem Neuroanat 8:283-305.

Martin WJ, Patrick SL, Coffin PO, Tsou K, Walker JM (1995) An examination of the central sites of action of cannabinoid-induced antinociception in the rat. Life Sci 56:2103-2109.
Martin WJ, Tsou K, Walker JM (1998) Cannabinoid receptor-mediated inhibition of the rat tail-flick reflex after microinjection into the rostral ventromedial medulla. Neurosci Lett 242:33-36.

Meng ID, Manning BH, Martin WJ, Fields HL (1998) An analgesia circuit activated by cannabinoids. Nature 395:381-383.

Ong WY, Mackie K (1999) A light and electron microscopic study of the CB1 cannabinoid receptor in primate brain. Neuroscience 92:1177-1191.

Pert A, Maxey G (1975) Asymmetrical cross-tolerance between morphine and scopolamine induced antinociception in the primate: differential sites of action. Psychopharmacologia 44:139-145.

Pert A, Yaksh T (1974) Sites of morphine induced analgesia in the primate brain: relation to pain pathways. Brain Res 80:135-140.

Pettit DA, Harrison MP, Olson JM, Spencer RF, Cabral GA (1998) Immunohistochemical localization of the neural cannabinoid receptor in rat brain. J Neurosci Res 51:391-402.

Peyron R, Garcia-Larrea L, Deiber MP, Cinotti L, Convers P, Sindou M, Mauguiere F, Laurent B (1995) Electrical stimulation of precentral cortical area in the treatment of central pain: electrophysiological and PET study. Pain 62:275-286.

Price DD, Von der Gruen A, Miller J, Rafii A, Price C (1985) A psychophysical analysis of morphine analgesia. Pain 22:261-269.

Rainville P, Duncan GH, Price DD, Carrier B, Bushnell MC (1997) Pain affect encoded in human anterior cingulate but not somatosensory cortex. Science 277:968-971.

Rebert CS, Hurd RE, Matteucci MJ, De LaPaz R, Enzmann DR (1991) A procedure for using proton magnetic resonance imaging to determine stereotaxic coordinates of the monkey's brain. J Neurosci Methods 39:109-113.

Rhudy JL, Meagher MW (2000) Fear and anxiety: divergent effects on human pain thresholds. Pain 84:65-75.

Richardson DE, Akil H (1977) Pain reduction by electrical stimulation in man. Part 1: Acute administration in periaqueductal and periventricular sites. J Neurosurg 47:178-183

Rosene DL, Roy NJ, Davis BJ (1986) A cryoprotection method that facilitates cutting frozen sections of whole monkey brains for histological and histochemical processing without freezing artifact. J Histochem Cytochem 34:1301-1315.

Saunders RC, Aigner TG, Frank JA (1990) Magnetic resonance imaging of the rhesus monkey brain: use for stereotactic neurosurgery. Exp Brain Res 81:443-446.

Schulz S, Schreff M, Koch T, Zimprich A, Gramsch C, Elde R, Hollt V (1998) Immunolocalization of two mu-opioid receptor isoforms (MOR1 and MOR1B) in the rat central nervous system. Neuroscience 82:613-622.

Stefanacci L, Amaral DG (2000) Topographic organization of cortical inputs to the lateral nucleus of the macaque monkey amygdala: a retrograde tracing study. J Comp Neurol 421:52-79.

Talbot JD, Marrett S, Evans AC, Meyer E, Bushnell MC, Duncan GH (1991) Multiple representations of pain in human cerebral cortex. Science 251:1355-1358.

Tallerida RJ, Murray RB (1987) Manual of pharmacologic calculations with computer programs, Ed 2. New York: Springer.

Tershner SA, Helmstetter FJ (2000) Antinociception produced by mu opioid receptor activation in the amygdala is partly dependent on activation of mu opioid and neurotensin receptors in the ventral periaqueductal gray. Brain Res 865:17-26.

Vivian JA, Kishioka S, Butelman ER, Broadbear J, Lee KO, Woods JH (1998) Analgesic, respiratory and heart rate effects of cannabinoid and opioid agonists in rhesus monkeys: antagonist effects of SR 141716A. J Pharmacol Exp Ther 286:697-703.

Walker EA, Butelman ER, DeCosta BR, Woods JH (1993) Opioid thermal antinociception in rhesus monkeys: receptor mechanisms and temperature dependency. J Pharmacol Exp Ther 267:280-286.

Willis WD, Westlund KN (1997) Neuroanatomy of the pain system and of the pathways that modulate pain. J Clin Neurophysiol 14:2-31.

Wolff BB, Kantor TJ, Jarvik ME, Laska E (1966) Response of experimental pain to analgesic drugs. I. Morphine, aspirin and placebo. Clin Pharmacol Ther 7:224-238.

Yang JC, Clark WC, Ngai SH, Berkowitz BA, Spector S (1979) Analgesic action and pharmacokinetics of morphine and diazepam in man. Anesthesiology 51:495-502. 